\title{
A Method for Quantifying Cervical Sagittal Morphology Using the Cervical Sagittal Triangle Area Coefficient
}

\section{Yingjun Guo}

Sichuan University West China Hospital

\section{Han Wang}

Sichuan University West China Hospital

Hao Liu ( $\square$ hxliuhao@126.com )

Sichuan University West China Hospital

\section{Beiyu Wang}

Sichuan University West China Hospital

\section{Chen Ding}

Sichuan University West China Hospital

\section{Yang Meng}

Sichuan University West China Hospital

Yi Yang

Sichuan University West China Hospital

\section{Research Article}

Keywords: Cobb angle, cervical sagittal morphology, area coefficient, dispersion coefficient, range of motion

Posted Date: July 27th, 2021

DOI: https://doi.org/10.21203/rs.3.rs-579200/v2

License: (c) (i) This work is licensed under a Creative Commons Attribution 4.0 International License. Read Full License 


\section{Abstract}

\section{Background}

A series of methods, which use angle to quantitatively evaluate cervical sagittal morphology cannot objectively reflect the advantages and disadvantages in some cases. In this study, we try to use the area methods to supplement it in above cases.

Methods

The Cobb angle, range of motion (ROM) of C2-7, and antero-posterior diameter of atlas (C1-APD) were measured at neutral, flexion, and extension X-ray radiographs of the cervical spine in all 191 patients. Patients were divided into Group A and Group B according to whether their cervical sagittal morphology can be objectively quantified with Cobb angle. Pearson correlation analysis was used to compare the consistency of the results, paired t-test was used to compare the dispersion coefficient, receiver operator characteristic (ROC) curve was used to evaluate the diagnostic value.

Results

The C5 vertebra was used as the vertex to construct the cervical sagittal triangle, and according to the different selection of the other two points, the triangle was further divided into four types. The Area Coefficient $(\mathrm{AC})$ was defined as "AC $=\frac{\text { (Areaofsagittaltriangle })}{\mathrm{C} 1-\mathrm{APD}^{2}}$ ". In Group A, whose cervical sagittal morphology could be objectively quantified with Cobb angle, the AC showed greatly consistency, while in Group B, it was less consistent. AC results have stronger predictive value for clinical symptoms in Group B. The dispersion coefficients of the results measured by the four area methods are significantly smaller than the Cobb angle. The results of quantifying cervical ROM by area methods were also in good agreement with Cobb angle.

Conclusion

Compared with Cobb angle, AC has better objectivity, stability, and clinical significance.

\section{Background}

Spinal degeneration is a pathological condition, which is closely related to age, working style, living habits and other factors. Topical muscle pain and a series of neurological abnormalities caused by compression of nerve tissue can significantly affect the quality of life. For all patients with cervical degenerative disease (CDD), X-ray is the most readily available first-hand information for doctors, with which we can have a more intuitive grasp of the degenerative condition. Lateral radiographs of the cervical spine show the sagittal morphology and help us understand the structural characteristics and assist surgeon in determining treatment strategies. 
The natural cervical sagittal morphology maintains a lordotic shape as a result of the wedge-shaped cervical vertebrae and the need to compensate for the kyphotic curvature of the thoracic spine ${ }^{1}$, and the angle of lordosis should be evenly distributed at all levels from $\mathrm{C} 2$ to $\mathrm{C} 7$. Cervical lordosis under the physiological condition can well buffer the impact force from the head and distribute it evenly to each intervertebral disc segment, which is very important for the protection of cranial soft tissue. Deviations from the sagittal morphology, such as the loss of lordosis or the development of kyphosis, are associated with pain and disability ${ }^{2-9}$.

As early as 1960, Borden et al. ${ }^{10}$ have already put forward the concept of "arch-string distance (ASD)", which is the maximum distance between the "arch" formed by cervical lordosis and the "string" formed by C2 and C7, whose original purpose is to objectively evaluate the degree of cervical lordosis and theoretically describe the cervical sagittal morphology. However, in the actual operation process, there're two aspects of defects: First, posterior wall of the cervical vertebra is irregular on the X-ray, and there are images overlapping, thus it is difficult to draw a complete and smooth "arch", especially for the patients with local kyphosis, so it is extremely difficult to determine the accurate ASD; Second, the ASD is the absolute value, which does not take into account the influence of size of patients. Therefore, the clinical application of it is very limited. Similarly, the measurement of cervical curvature index $(\mathrm{CCl})^{11}$ has clearly defined the selection of reference points, however, there is still the problem of images overlapping, and it requires the data of ASD of each segment separately, which is a complicated process and difficult to be applied in practice. By contrast, the measurement of angles seems much easier.

Cobb angle was first used to evaluate the degree of scoliosis ${ }^{12}$, and later expanded to be a quantitative indicator of the degree of cervical lordosis. Cobb angle can directly quantify the cervical sagittal morphology of patients, and it is also the most conventional method at present. Therefore, "cervical curvature" is often used instead of "cervical sagittal morphology". In addition to Cobb angle, there are other methods for measuring cervical curvature, such as centroid measurement of cervical lordosis $(\mathrm{CCL})^{13}$ and Harrison method ${ }^{14}$, which have similar principles. However, in practice, we also found that the measurement of cervical curvature could not objectively reflect the "cervical sagittal morphology" of patients in some cases, including: (1) Osteophyte of C2/C7; (2) Local kyphosis; (3) Curvature concentration. Under such conditions, the $\mathrm{C} 2-7$ curvature appears to be acceptable, but in fact the patient's cervical sagittal morphology is not ideal. In addition, no matter which measurement method is used, the cervical curvature is determined by two lines, so the results are relatively unstable, while different people choose different reference points, resulting in large differences in the final data.

Here we tried to use "area" instead of "angle" to evaluate the cervical sagittal morphology, to avoid above situations to some extent. The "cervical sagittal triangle" was constructed by selecting the appropriate points and measuring its area, and the typical cervical size reference was selected to offset the influence of the size of patients' cervical spine, as shown in Figure-1. The purpose of this study was to preliminarily determine the applicability of "area method" in the evaluation of cervical sagittal morphology. 


\section{Methods}

\section{Study Design}

The present study was conducted in one spine center, and a total of 191 patients who suffered from CDDrelated symptoms were consecutively included into the study. The inclusion criteria for the present study were clearly defined, as follows: (1) Patients aged from 18 to 75 years; (2) There was no obvious destruction or deformity of cervical bone. (3) The cervical spine of the patient had not received surgery; (4) The patient had a complete cervical neutral sagittal and flexion/extension X-ray, and the margins of the $\mathrm{C} 2$ to $\mathrm{C} 7$ vertebral bodies were clear and complete, which could meet the requirements of the measurement of relevant imaging indicators.

\section{Radiographic Evaluation}

Lateral cervical radiograph examination was performed. The tube to subject distance was 72 inches, with the radiographic tube centered at the $\mathrm{C} 4-\mathrm{C} 5$ intervertebral disc without magnification. Lateral radiographs of the cervical spine were taken when the patient was in a comfortable standing position, with the upper extremities positioned naturally at the sides of the trunk, while looking straight forward. All radiograph images were transferred to a computer in DICOM format, and the measurements were performed by two independent observers. The measured items of the cervical sagittal parameters in the radiographs mainly included the antero-posterior diameter of atlas (C1-APD) the Cobb angle of C2-7 in neutral, flexion and extension positions. According to the X-ray results, patients who could use Cobb angle to accurately assess cervical sagittal morphology were included in Group A. Patients with the following three conditions, which we believed that the Cobb angle could not objectively reflect the defects of the cervical sagittal morphology, were included in Group B:

1. Osteophyte of $\mathrm{C} 2 / \mathrm{C7}$ : Obvious osteophyte formation in the inferior endplate of $\mathrm{C} 2$ or $\mathrm{C7}$;

2. Local kyphosis: The cervical spine as a whole is lordosis while it shows local kyphosis in one or several segments.

3. Curvature concentration: Over $80 \%$ of the curvature is concentrated in $\mathrm{C} 2-3$ or $\mathrm{C} 6-7$, no matter it is lordosis or kyphosis;

\section{Clinical Evaluation}

The clinical symptoms of each patient were consulted and recorded, which mainly included four aspects:

1. Neck or shoulder pain;

2. Arm pain;

3. Myelopathy-related symptoms: Numbness and weakness of bilateral limbs, feeling of stepping on cotton on both feet, delicate clumsy movements of both hands, dysfunction of urine and feces, etc.

4. Sympathetic or vertebral artery (VA)-related symptoms: Head, face or trunk numbness, chills, Loading [MathJax]/jax/output/CommonHTML/jax.js and other sympathetic-related symptoms; migraine, vertigo 
and other VA-related symptoms. The clinical manifestations of these two types of cervical spondylosis are largely overlapping, so there is no further differentiation.

\section{Statistical Analysis}

The data analysis and image creation were conducted using GraphPad Prism version 8.0.0 (GraphPad Software, Inc, San Diego). The level of significance was set at $P<0.05$. Chi-squared analysis and unpaired t-test were used, respectively, for categorical and continuous data between groups, while paired t-test was used to compare the data of the one group from different measurement methods. Pearson correlation analysis was used to analyze the correlation between data of different groups. Dispersion coefficient is used to evaluate the level of fluctuation between the measurement results of different personnel. Receiver operator characteristic (ROC) curve and calculation of area under curve (AUC) were used to evaluate the diagnostic value of cervical sagittal morphology for CDD-related clinical symptoms. A statistical power with a significant level (alpha) of 0.05 was calculated using the G-Power software (version 3.1.9.4) when there was a statistical difference ${ }^{15}$. All values were expressed in mean \pm standard deviation or percentage.

\section{Results}

\section{Basic Information of Included Patients}

According to the inclusion criteria, 191 patients were included in this study, and the specific information were listed in Table-1. As mentioned above, patients whose cervical sagittal morphology could be objectively quantified by Cobb angle method were included in Group A and the remaining patients, who suffered from "Osteophyte of C2/C7", "Local kyphosis", or "Curvature concentration", were included in Group B.

\section{Design And Description Of Area Methods}

Considering that in the vast majority of cases, the C5 body is the apex of cervical lordosis, we selected C2, $\mathrm{C} 5$, and $\mathrm{C} 7$ as the three points of the sagittal triangle. Specific points selection methods are further divided into the following four:

Method-1: Anterior-inferior point of C7 - Midpoint of anterior edge of C5 - Midpoint of anterior edge of C7 (Figure-1A);

Method-2: Posterior-inferior point of C7 - Midpoint of posterior edge of C5 -- Midpoint of posterior edge of C7 (Figure-1B);

Method-3: Midpoint of inferior endplate of C2 - Midpoint of anterior edge of C5 -- Midpoint of inferior endplate of C7 (Figure-1C); 
Method-4: Midpoint of inferior endplate of C2 - Midpoint of anterior edge of C5 -- Midpoint of superior endplate of C7 (Figure-1D).

In "Method-1" and "Method-2", the midpoint of the anterior margin of the vertebral body was selected mainly to avoid the influence of C5 or C7 osteophytes on the area measurement. In "Method-3" and "Method-4", the midpoint of the inferior endplate was selected to avoid the effect of C2 osteophytes on the area measurement. The Area Coefficient (AC) value was negative when the midpoint of the $\mathrm{C} 5$ anterior edge fell on the right side of the base of the cervical sagittal triangle. In addition, in order to offset the influence of patients' body size, the C1-APD ${ }^{2}$ (Figure-1) was used as the reference value, and the AC obtained by comparing the area value with it was used as the final index: ${ }^{\mathrm{AC}}=\frac{\text { (Area of sagittal triangle })_{n}}{{\mathrm{C} 1-\mathrm{APD}^{2}}}$.

\section{There Was Strong Consistency in Results between Area Methods and Cobb Angle Method in Group A}

For Group A patients, Cobb angle can objectively reflect the advantages and defects of the cervical sagittal morphology. Therefore, we quantified the cervical sagittal morphology of this part of patients by using both Cobb angle method and area method, and conducted correlation analysis of the two groups of data. As shown in the Figure-2A and Figure-2B, the correlations between the measurement results of Method-1 $(r=0.8480, P<0.0001, S P=100.00 \%)$ and Method-2 $(r=0.8321, P<0.0001, S P=100.00 \%)$ and the measurement results of Cobb angle method were strongly correlated. As shown in the Figure-2C and Figure-2D, the measurement results of the latter two area methods, Method-3 $(r=0.7627, P<0.0001, S P=$ $100.00 \%)$ and Method-4 $(r=0.7157, P<0.0001, S P=100.00 \%)$ have relatively poor correlation with the measurement results of Cobb angle method. We consider that the latter two methods may be influenced by the antero-posterior diameters of the vertebra. In the measurement process, we found that the accuracy of Method-2 was slightly lower than that of Method-1, mainly because of that the posterior edge of the vertebral body was relatively unclear and there're some images overlapping.

\section{Results of Area Methods Were More Objective in Group B}

According to the grouping conditions mentioned above, 68 patients were screened out from 191 patients who met the Group B criteria. Among them, 3 cases were identified as "Osteophyte of C2/C7", 47 cases were identified as "Local kyphosis", and 18 cases were identified as "Curvature concentration". It can be seen that a significant proportion (35.60\%) of the patients had cervical sagittal morphology that was not suitable for evaluation by Cobb angle method. Similarly, after quantifying the cervical sagittal morphology of Group B patients using two methods, correlation analysis was conducted for the two groups of data. As shown in Figure-3, the correlations obtained by the four methods were relatively poor, suggesting that there were differences in the cervical sagittal morphology described by Cobb angle method and area methods in this part of patients. Further, we selected a representative group of patients 
of the C2-7 Cobb angle of all four patients was basically the same. However, in the three patients of Group B (Figure-4F, -4K, -4P), different from Group A (Figure-4A), due to the structural abnormality of their cervical vertebrae, the size of Cobb angle could not accurately reflect the defects of the cervical sagittal morphology. From the results of the area methods, we can see that although the Cobb angle is of the same size, the $A C$ values of patient in Group $A$ (Figure-4B to $-4 \mathrm{E}$ ) were significantly higher than that of the three patients in Group B (Figure-4G to $-4 \mathrm{~J}$, Figure-4L to -40 , Figure-4Q to $-4 \mathrm{~T}$ ), suggesting that the cervical sagittal morphology of patient in Group A is actually better.

\section{Stronger Correlation between Results of Area Methods and Clinical Indicators Was Identified in Group B}

In order to evaluate the diagnostic value of different quantitative methods on CDD-related clinical indicators, the ROC curve between the quantitative results of Cervical sagittal morphology and clinical indicators is constructed. As shown in Figure-5 and Table-2, both Cobb angle method and area methods have certain diagnostic value for the occurrence of "Neck or shoulder pain" and "Sympathetic or VArelated symptoms" in the whole patient group: the greater the quantified value of cervical sagittal morphology, the lower the incidence of these symptoms. As shown in Figure- 6 and Table-3, similar results were also obtained in Group A. However, in Group B, as shown in Figure-7 and Table-4, the results of area method still had predictive value for the above two aspects of symptoms, while the predictive ability of Cobb angle method was significantly reduced.

\section{Stability of Area Method Was Better than That of Cobb Angle}

Another advantage of the area methods is the stability of results. Because the inferior endplate of C2 and $\mathrm{C} 7$ is not regular in most cases, different measurers may choose different reference points when selecting the standard line, thus resulting in inconsistent measurement results, which is also a situation we often encounter in our daily work. However, in the area methods, the location difference of selected points will not cause the obvious change of the size of the triangle area, that is to say, the stability of AC is better. To prove it, five measurers independently quantified the cervical sagittal morphology in 191 patients using the Cobb angle method and the area methods, so that five independent results were obtained for each measurement method in each sample. Further, the dispersion coefficient of the five independent results was calculated and compared. The results are shown in the Figure-8. It can be seen that the dispersion coefficients of the measurement results of the four area methods are significantly smaller than those of Cobb angle method.

\section{Area Methods Had No Advantage In Quantifying Cervical}


In this section, we explored the applicability of the area methods in evaluating cervical range of motion (ROM). The AC values in the extension and flexion positions were measured respectively, and the difference between the two results was used as a quantitative index of cervical ROM, and the correlation analysis was further conducted with the ROM calculated by conventional Cobb angle method. As shown in the Figure-9, the results measured by the four area methods are strongly correlated with those by the Cobb angle method. However, in the process of subtraction, the defects and instability of the Cobb angle method are offset, and the results are objective and realistic enough. Therefore, although the results of the area methods have a strong correlation with Cobb angle, it does not have any advantages.

\section{Discussion}

As mentioned earlier, the ideal cervical sagittal morphology is lordosis, whereas the loss of cervical curvature or kyphosis were considered to be abnormal ${ }^{1}$. As for whether excessive lordosis is an abnormal form, the relevant reports are still very limited. The study on the correlation between cervical curvature and clinical symptoms has always been a clinical focus. Grob et al. pointed out in their study that patients with poor cervical curvature tended to have higher degree of neck pain ${ }^{2}$. Similarly, after measuring cervical curvature in 277 patients, McAviney et al. found that patients with poor curvature were more likely to have symptoms of cervical pain ${ }^{3}$. In addition, some studies have pointed out that cervical kyphosis can also lead to cervical myelopathy, the mechanism of which is that cervical kyphosis can lead to vertebral compression of the spinal cord and increased spinal cord tension ${ }^{4,5}$. At the same time, the deterioration of cervical curvature can also be used as the imaging manifestation for cervical degeneration ${ }^{16}$. Broadly speaking, the accurate quantification of cervical sagittal morphology is helpful for us to evaluate the functional status and degenerative condition.

After Cobb angle became widely used, "cervical curvature" became a synonym for "cervical sagittal morphology". However, relatively few publications have defined these normative values for cervical curvature $^{1}$. As mentioned above, based on the specific imaging findings, we conclude that there are three situations in which the Cobb angle method is not appropriate to use, in which it cannot objectively reflect the real condition of cervical sagittal morphology. In some patients, the curvature of their cervical vertebrae was straight overall, but due to the presence of large osteophytes in the anterior edge of the inferior endplate at C7, or the large Cobb angle at C2-3/C6-7, the measurement results of Cobb angle at C2-7 were satisfactory, as shown in Figure-4, but the sagittal shape of their cervical vertebrae was actually not good. Among the 191 patients included in our study, 35.60\% (68/191) of them had the above condition. It can be seen that a significant proportion of patients have cervical sagittal morphology that is not suitable for evaluation by Cobb angle method. In this case, we attempted to use the area methods instead of the Cobb angle method to quantitatively evaluate cervical sagittal morphology.

At the beginning of the study, in order to reflect the sagittal morphology of the entire cervical spine as much as possible, we tried to include all vertebral bodies into the area composition of the sagittal plane. However, we found that such an area measurement method is too complicated to be used on a large Loading [MathJax]/jax/output/CommonHTML/jax.js 
scale. Therefore, we decided to use the "sagittal triangle" as a representation of cervical sagittal morphology. For it, we first identified the midpoint of the $\mathrm{C} 5$ anterior edge, which is the theoretical apex of cervical lordosis. For the position of the other two points, we divided it into four methods according to the principles of "high feasibility" and "high accuracy", as shown in Figure-1. Another part worth exploring is the choice of reference of body size. In fact, we chose patient height at the start of the study because it is more readily available and is the most direct proxy for body size. However, the actual analysis results were not ideal. We considered that the height could not completely represent the size of the patient's cervical spine. After all, there was no significant difference in the size of the head and neck of people of different heights. Therefore, we finally chose the "C1-APD2" as a reference to offset the impact of the difference in patient body size. However, in practice, we still encountered some problems :(1) In a very small number of patients, part of $\mathrm{C} 1$ is obscured by the basilar structure, which affects the measurement of C1-APD; (2) We are not sure whether individual differences in C1-APD will affect the results. From the current results, it can be seen that C1-APD has fulfilled its task as a reference value well, but whether there is a better choice is also a part that needs to be improved.

In order to verify the evaluation effectiveness of AC, we selected 123 patients whose cervical sagittal morphology could be objectively quantified by Cobb angle method, namely Group A. Cobb angle method and area methods were used, and the results of the two methods were in good agreement, indicating that area methods can objectively reflect the advantages and defects of cervical sagittal morphology. Secondly, for Group B, the correlation among the results from different methods was poor. As shown in Figure-4, although the Cobb angle values of C2-7 were similar, in fact, the cervical sagittal morphology of the three patients in Group B was significantly poorer than that of Group A, and the AC values of the area methods well reflected this difference. Further, we evaluate the diagnostic ability of the quantitative results of cervical sagittal morphology on CDD-related clinical indicators. The results showed that, in Group A, both Cobb angle method and area methods can predict the occurrence of "Neck or shoulder pain" and "Sympathetic or VA-related symptoms" to a certain extent, which is consistent with the conclusions of previous reports, as shown in Table-3. However, in Group B, the diagnostic value of Cobb angle method was greatly reduced. This also suggests that the assessment of area methods are of more clinical significance for Group B patients (Table-4). In the course of the study, we noticed another advantage of the area methods, that is, its stability is better. This is because the area of the sagittal triangle does not change significantly due to the fretting of the selected location of points. As shown in Figure-8, the results of dispersion coefficient proved the above inference, that is, the difference of $A C$ values measured by different personnel is significantly small.

Cobb angle method could provides an objective and realistic assessment of ROM in the cervical spine. In contrast, although the measurement results of the area methods are in good agreement with those of Cobb angle method, there is no advantage. Because, as long as the reference points selected in the flexion and extension positions is the same, the ROM measured by the Cobb angle method is accurate, regardless of whether the structure of cervical spine is abnormal or not, and regardless of the points location of the individual selected. Furthermore, flexion and extension of the cervical spine are not a 
standard circular motion around the fixed center, but a complex multi-segment composite motion, whose trajectory can not be simply described by the change of the area of the sagittal triangle.

In summary, Method-1, namely, "Anterior-inferior point of C7 - Midpoint of anterior edge of C5 - Midpoint

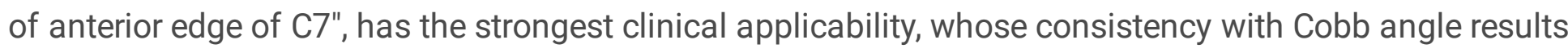
is greatest in Group A. It is not affected by the antero-posterior diameters of the vertebra as is the problem with Methods-3 and Methods-4. At the same time, since the anterior edge of the vertebra from $\mathrm{C} 2$ to $\mathrm{C} 7$ is relatively clear in the majority of the neutral sagittal radiographic images of the cervical spine, it will not be affected by the inaccurate selection points caused by the lack of clarity of the posterior edge of the vertebra, as in Method-2.

Original data will be added to this article in the public form of the Supplement (Supplementary Material1). As a single center, we have very limited data, so we hope that spinal surgeons from all over the world can discuss and further validate and refine the design of the "area method".

\section{Conclusion}

In general, the area methods, which shows better objectivity and stability, can supplement and modify the evaluation results of cervical sagittal morphology quantified with Cobb angle in some cases, but it cannot replace it, especially in the measurement of dynamic indicators. However, the significance of this study lies more in putting forward a new idea and emphasizing that "cervical curvature" is only a method to evaluate the "cervical sagittal morphology", and cannot fully represent it.

\section{Abbreviations}

AC

area coefficient

ASD

arch-string distance

AUC

area under curve

C1-APD

anterio-posterior diameter of atlas

$\mathrm{CCl}$

cervical curvature index

CCL

centroid measurement of cervical lordosis

CDD

cervical degenerative disease

IRB

institutional review hoard Loading [MathJax]/jax/output/CommonHTML/jax.js 
ROC

receiver operator characteristic

ROM

range of motion

VA

vertebral artery

\section{Declarations}

Ethics approval: This study has institutional review board (IRB) approval / research ethics committee approval, and the document has been attached to the submission.

Consent of participate: All of the 191 patients gave informed consent and agreed to participate in the study.

Consent for publication: Written informed consent for publication was obtained from all participants.

Availability of data and material: The original data are available and attached to the submission as the supplement.

Competing interests: The authors declare that they have no conflict of interest.

Funding: This study was funded by the 1.3.5 Project for Disciplines of Excellence, West China Hospital, Sichuan University (No. ZYJC18029, Hao Liu).

\section{Authors' contributions:}

Yingjun Guo: (1) Radiographic measurement and data analysis; (2)Article writing;

Han Wang: (1) Radiographic measurement; (2) Application of ethical certification;

Hao Liu: (1) Study design; (2) Instructor of the study;

Beiyu Wang: (1) Radiographic measurement; (2) Language polishing;

Chen Ding: Radiographic measurement;

Yang Meng: Radiographic measurement;

Yi Yang: (1) Guidance of radiographic measurement; (2) Language polishing;

\section{Acknowledgement}

We would like to express our sincere appreciation for the support from patients who have agreed to narticinate in this studv Loading [MathJax]/jax/output/CommonHTML/jax.js 


\section{References}

1. Scheer JK, Tang JA, Smith JS, et al. Cervical spine alignment, sagittal deformity, and clinical implications: a review. J Neurosurg Spine. Aug 2013;19(2):141-59. doi:10.3171/2013.4.SPINE12838

2. Grob D, Frauenfelder H, Mannion AF. The association between cervical spine curvature and neck pain. Eur Spine J. May 2007;16(5):669-78. doi:10.1007/s00586-006-0254-1

3. McAviney J, Schulz D, Bock R, Harrison DE, Holland B. Determining the relationship between cervical lordosis and neck complaints. J Manipulative Physiol Ther. Mar-Apr 2005;28(3):187-93. doi:10.1016/j.jmpt.2005.02.015

4. Albert TJ, Vacarro A. Postlaminectomy kyphosis. Spine (Phila Pa 1976). Dec 15 1998;23(24):2738-45. doi:10.1097/00007632-199812150-00014

5. Deutsch H, Haid RW, Rodts GE, Mummaneni PV. Postlaminectomy cervical deformity. Neurosurg Focus. Sep 15 2003;15(3):E5. doi:10.3171/foc.2003.15.3.5

6. Ames CP, Smith JS, Scheer JK, et al. Impact of spinopelvic alignment on decision making in deformity surgery in adults: A review. J Neurosurg Spine. Jun 2012;16(6):547-64. doi:10.3171/2012.2.SPINE11320

7. Gore DR. Roentgenographic findings in the cervical spine in asymptomatic persons: a ten-year followup. Spine (Phila Pa 1976). Nov 15 2001;26(22):2463-6. doi:10.1097/00007632-200111150-00013

8. Hardacker JW, Shuford RF, Capicotto PN, Pryor PW. Radiographic standing cervical segmental alignment in adult volunteers without neck symptoms. Spine (Phila Pa 1976). Jul 1 1997;22(13):1472-80; discussion 1480. doi:10.1097/00007632-199707010-00009

9. Tang JA, Scheer JK, Smith JS, et al. The impact of standing regional cervical sagittal alignment on outcomes in posterior cervical fusion surgery. Neurosurgery. Mar 2015;76 Suppl 1:S14-21; discussion S21. doi:10.1227/01.neu.0000462074.66077.2b

10. Borden AG, Rechtman AM, Gershon-Cohen J. The normal cervical lordosis. Radiology. May 1960;74:806-9. doi:10.1148/74.5.806

11. Takeshita K, Murakami M, Kobayashi A, Nakamura C. Relationship between cervical curvature index (Ishihara) and cervical spine angle (C2-7). J Orthop Sci. 2001;6(3):223-6. doi:10.1007/s007760100038

12. Whittle MW, Evans M. Instrument for measuring the Cobb angle in scoliosis. Lancet. Feb 24 1979;1(8113):414. doi:10.1016/s0140-6736(79)90887-0

13. Ohara A, Miyamoto K, Naganawa T, Matsumoto K, Shimizu K. Reliabilities of and correlations among five standard methods of assessing the sagittal alignment of the cervical spine. Spine (Phila Pa 1976). Oct 15 2006;31(22):2585-91; discussion 2592. doi:10.1097/01.brs.0000240656.79060.18

14. Harrison DD, Janik TJ, Troyanovich SJ, Holland B. Comparisons of lordotic cervical spine curvatures to a theoretical ideal model of the static sagittal cervical spine. Spine (Phila Pa 1976). Mar 15 1996;21(6):667-75. doi:10.1097/00007632-199603150-00002 
15. Faul F, Erdfelder E, Lang AG, Buchner A. G*Power 3: a flexible statistical power analysis program for the social, behavioral, and biomedical sciences. Behav Res Methods. May 2007;39(2):175-91. doi:10.3758/bf03193146

16. Bao H, Varghese J, Lafage R, et al. Principal Radiographic Characteristics for Cervical Spinal Deformity: A Health-related Quality-of-life Analysis. Spine (Phila Pa 1976). Sep 15 2017;42(18):13751382. doi:10.1097/BRS.0000000000002144

\section{Tables}

Table-1 Basic Information of Included Cases

\begin{tabular}{|c|c|c|c|c|c|c|}
\hline \multicolumn{2}{|c|}{ Items } & Total & Group A & Group B & $\begin{array}{l}\mathrm{P} \\
\text { Value }\end{array}$ & $\begin{array}{l}\text { Statistical } \\
\text { Power }\end{array}$ \\
\hline \multicolumn{2}{|c|}{ Number of Patients } & 191 & 123 & 68 & $(-)$ & $(-)$ \\
\hline \multirow[t]{4}{*}{ Age } & Average(years) & $52.60 \pm 11.06$ & $53.38 \pm 10.49$ & $51.19 \pm 11.91$ & 0.1920 & $(-)$ \\
\hline & $40 \rrbracket A g e \geq 0$ & 16 & 7 & 9 & \multirow[t]{3}{*}{0.1647} & \multirow[t]{3}{*}{$(-)$} \\
\hline & $65 \llbracket A g e \geq 40$ & 144 & 94 & 50 & & \\
\hline & Age $\geq 65$ & 31 & 22 & 9 & & \\
\hline \multirow[t]{2}{*}{ Sex } & Male & 101 & 64 & 37 & \multirow[t]{2}{*}{0.7524} & \multirow[t]{2}{*}{$(-)$} \\
\hline & Female & 90 & 59 & 31 & & \\
\hline \multicolumn{2}{|c|}{ Weight (kg) } & $64.34 \pm 10.01$ & $64.35 \pm 9.76$ & $64.31 \pm 10.45$ & 0.9786 & $(-)$ \\
\hline \multicolumn{2}{|c|}{ Height (cm) } & $163.37 \pm 9.53$ & $163.20 \pm 9.41$ & $163.68 \pm 9.73$ & 0.7441 & $(-)$ \\
\hline \multicolumn{2}{|c|}{$\begin{array}{l}\text { C2-7 Cobb Angle } \\
\text { (degree) }\end{array}$} & $11.62 \pm 11.59$ & $14.05 \pm 11.71$ & $7.10 \pm 9.94$ & 0.0002 & $98.79 \%$ \\
\hline \multicolumn{2}{|c|}{ C2-7 ROM (degree) } & $48.51 \pm 13.93$ & $48.16 \pm 13.96$ & $49.15 \pm 13.86$ & 0.6414 & $(-)$ \\
\hline
\end{tabular}

*Note. ROM, range of motion

Table-2 ROC Analysis of Cervical Sagittal Morphology and Clinical Indicators in All Patients 


\begin{tabular}{|c|c|c|c|c|c|c|}
\hline \multirow[t]{2}{*}{ Items } & & & \multirow[t]{2}{*}{ AUC } & \multicolumn{2}{|l|}{$95 \% \mathrm{Cl}$} & \multirow[t]{2}{*}{$P$ Value } \\
\hline & & & & Lower & Upper & \\
\hline \multirow[t]{5}{*}{ Neck or Shoulder Pain } & \multicolumn{2}{|c|}{ Cobb Angle Method } & 0.65 & 0.57 & 0.73 & 0.0004 \\
\hline & \multirow[t]{4}{*}{$\begin{array}{l}\text { Area } \\
\text { Methods }\end{array}$} & $\begin{array}{l}\text { Method- } \\
1\end{array}$ & 0.70 & 0.63 & 0.78 & $\square 0.0001$ \\
\hline & & $\begin{array}{l}\text { Method- } \\
2\end{array}$ & 0.68 & 0.60 & 0.75 & $\square 0.0001$ \\
\hline & & $\begin{array}{l}\text { Method- } \\
3\end{array}$ & 0.70 & 0.62 & 0.77 & $\square 0.0001$ \\
\hline & & $\begin{array}{l}\text { Method- } \\
4\end{array}$ & 0.70 & 0.63 & 0.78 & $\square 0.0001$ \\
\hline \multirow[t]{5}{*}{ Arm Pain } & \multicolumn{2}{|c|}{ Cobb Angle Method } & 0.51 & 0.42 & 0.60 & 0.8493 \\
\hline & \multirow[t]{4}{*}{$\begin{array}{l}\text { Area } \\
\text { Methods }\end{array}$} & $\begin{array}{l}\text { Method- } \\
1\end{array}$ & 0.52 & 0.44 & 0.61 & 0.6041 \\
\hline & & $\begin{array}{l}\text { Method- } \\
2\end{array}$ & 0.53 & 0.44 & 0.62 & 0.4864 \\
\hline & & $\begin{array}{l}\text { Method- } \\
3\end{array}$ & 0.55 & 0.46 & 0.64 & 0.2591 \\
\hline & & $\begin{array}{l}\text { Method- } \\
4\end{array}$ & 0.54 & 0.46 & 0.63 & 0.3345 \\
\hline \multirow[t]{5}{*}{ Myelopathy-Related Symptoms } & \multicolumn{2}{|c|}{ Cobb Angle Method } & 0.58 & 0.50 & 0.66 & 0.0631 \\
\hline & \multirow[t]{4}{*}{$\begin{array}{l}\text { Area } \\
\text { Methods }\end{array}$} & $\begin{array}{l}\text { Method- } \\
1\end{array}$ & 0.55 & 0.46 & 0.63 & 0.2772 \\
\hline & & $\begin{array}{l}\text { Method- } \\
2\end{array}$ & 0.55 & 0.47 & 0.63 & 0.2407 \\
\hline & & $\begin{array}{l}\text { Method- } \\
3\end{array}$ & 0.52 & 0.44 & 0.60 & 0.6623 \\
\hline & & $\begin{array}{l}\text { Method- } \\
4\end{array}$ & 0.52 & 0.43 & 0.60 & 0.7225 \\
\hline \multirow{4}{*}{$\begin{array}{l}\text { Sympathetic or VA-Related } \\
\text { Symptoms }\end{array}$} & \multicolumn{2}{|c|}{ Cobb Angle Method } & 0.63 & 0.54 & 0.71 & 0.0039 \\
\hline & \multirow[t]{3}{*}{$\begin{array}{l}\text { Area } \\
\text { Methods }\end{array}$} & $\begin{array}{l}\text { Method- } \\
1\end{array}$ & 0.65 & 0.57 & 0.73 & 0.0005 \\
\hline & & $\begin{array}{l}\text { Method- } \\
2\end{array}$ & 0.64 & 0.56 & 0.72 & 0.0012 \\
\hline & & $\begin{array}{l}\text { Method- } \\
3\end{array}$ & 0.66 & 0.58 & 0.74 & 0.0003 \\
\hline Loading [MathJax]/jax/output/CommonH & & Method- & 0.65 & 0.57 & 0.73 & 0.0006 \\
\hline
\end{tabular}


*Note. VA, vertebral artery; AUC, area under curve; $\mathrm{Cl}$, confidence interval

Table-3 ROC Analysis of Cervical Sagittal Morphology and Clinical Indicators in Group A 


\begin{tabular}{|c|c|c|c|c|c|c|}
\hline \multirow[t]{2}{*}{ Items } & & & \multirow[t]{2}{*}{ AUC } & \multicolumn{2}{|l|}{$95 \% \mathrm{Cl}$} & \multirow{2}{*}{$\begin{array}{l}\mathrm{P} \\
\text { Value }\end{array}$} \\
\hline & & & & Lower & Upper & \\
\hline \multirow[t]{5}{*}{ Neck or Shoulder Pain } & \multicolumn{2}{|c|}{ Cobb Angle Method } & 0.65 & 0.56 & 0.75 & 0.0037 \\
\hline & \multirow[t]{4}{*}{$\begin{array}{l}\text { Area } \\
\text { Methods }\end{array}$} & $\begin{array}{l}\text { Method- } \\
1\end{array}$ & 0.65 & 0.56 & 0.75 & 0.0034 \\
\hline & & $\begin{array}{l}\text { Method- } \\
2\end{array}$ & 0.67 & 0.57 & 0.76 & 0.0018 \\
\hline & & $\begin{array}{l}\text { Method- } \\
3\end{array}$ & 0.68 & 0.58 & 0.77 & 0.0009 \\
\hline & & $\begin{array}{l}\text { Method- } \\
4\end{array}$ & 0.67 & 0.57 & 0.76 & 0.0016 \\
\hline \multirow[t]{5}{*}{ Arm Pain } & \multicolumn{2}{|c|}{ Cobb Angle Method } & 0.47 & 0.36 & 0.58 & 0.6216 \\
\hline & \multirow[t]{4}{*}{$\begin{array}{l}\text { Area } \\
\text { Methods }\end{array}$} & $\begin{array}{l}\text { Method- } \\
1\end{array}$ & 0.52 & 0.42 & 0.63 & 0.6717 \\
\hline & & $\begin{array}{l}\text { Method- } \\
2\end{array}$ & 0.51 & 0.40 & 0.62 & 0.8426 \\
\hline & & $\begin{array}{l}\text { Method- } \\
3\end{array}$ & 0.55 & 0.44 & 0.65 & 0.4117 \\
\hline & & $\begin{array}{l}\text { Method- } \\
4\end{array}$ & 0.55 & 0.45 & 0.66 & 0.3505 \\
\hline \multirow[t]{5}{*}{ Myelopathy-Related Symptoms } & \multicolumn{2}{|c|}{ Cobb Angle Method } & 0.60 & 0.50 & 0.70 & 0.0663 \\
\hline & \multirow[t]{4}{*}{$\begin{array}{l}\text { Area } \\
\text { Methods }\end{array}$} & $\begin{array}{l}\text { Method- } \\
1\end{array}$ & 0.56 & 0.46 & 0.66 & 0.2445 \\
\hline & & $\begin{array}{l}\text { Method- } \\
2\end{array}$ & 0.57 & 0.47 & 0.67 & 0.1935 \\
\hline & & $\begin{array}{l}\text { Method- } \\
3\end{array}$ & 0.51 & 0.40 & 0.61 & 0.8873 \\
\hline & & $\begin{array}{l}\text { Method- } \\
4\end{array}$ & 0.50 & 0.39 & 0.60 & 0.9596 \\
\hline \multirow{4}{*}{$\begin{array}{l}\text { Sympathetic or VA-Related } \\
\text { Symptoms }\end{array}$} & \multicolumn{2}{|c|}{ Cobb Angle Method } & 0.64 & 0.54 & 0.74 & 0.0123 \\
\hline & \multirow[t]{3}{*}{$\begin{array}{l}\text { Area } \\
\text { Methods }\end{array}$} & $\begin{array}{l}\text { Method- } \\
1\end{array}$ & 0.63 & 0.52 & 0.74 & 0.0199 \\
\hline & & $\begin{array}{l}\text { Method- } \\
2\end{array}$ & 0.63 & 0.52 & 0.74 & 0.0177 \\
\hline & & $\begin{array}{l}\text { Method- } \\
3\end{array}$ & 0.66 & 0.56 & 0.76 & 0.0045 \\
\hline \multicolumn{2}{|c|}{ Loading [MathJax]/jax/output/CommonHTML/jax.js } & Method- & 0.65 & 0.54 & 0.75 & 0.0075 \\
\hline
\end{tabular}


*Note. VA, vertebral artery; AUC, area under curve; $\mathrm{Cl}$, confidence interval

Table-4 ROC Analysis of Cervical Sagittal Morphology and Clinical Indicators in Group B 


\begin{tabular}{|c|c|c|c|c|c|c|}
\hline \multirow[t]{2}{*}{ Items } & & & \multirow[t]{2}{*}{ AUC } & \multicolumn{2}{|l|}{$95 \% \mathrm{Cl}$} & \multirow{2}{*}{$\begin{array}{l}\mathrm{P} \\
\text { Value }\end{array}$} \\
\hline & & & & Lower & Upper & \\
\hline \multirow[t]{5}{*}{ Neck or Shoulder Pain } & \multicolumn{2}{|c|}{ Cobb Angle Method } & 0.59 & 0.43 & 0.75 & 0.2348 \\
\hline & \multirow[t]{4}{*}{$\begin{array}{l}\text { Area } \\
\text { Methods }\end{array}$} & $\begin{array}{l}\text { Method- } \\
1\end{array}$ & 0.75 & 0.62 & 0.88 & 0.0012 \\
\hline & & $\begin{array}{l}\text { Method- } \\
2\end{array}$ & 0.66 & 0.51 & 0.80 & 0.0403 \\
\hline & & $\begin{array}{l}\text { Method- } \\
3\end{array}$ & 0.69 & 0.55 & 0.83 & 0.0114 \\
\hline & & $\begin{array}{l}\text { Method- } \\
4\end{array}$ & 0.73 & 0.60 & 0.87 & 0.0021 \\
\hline \multirow[t]{5}{*}{ Arm Pain } & \multicolumn{2}{|c|}{ Cobb Angle Method } & 0.55 & 0.41 & 0.70 & 0.4639 \\
\hline & \multirow[t]{4}{*}{$\begin{array}{l}\text { Area } \\
\text { Methods }\end{array}$} & $\begin{array}{l}\text { Method- } \\
1\end{array}$ & 0.51 & 0.37 & 0.66 & 0.8408 \\
\hline & & $\begin{array}{l}\text { Method- } \\
2\end{array}$ & 0.56 & 0.42 & 0.71 & 0.4031 \\
\hline & & $\begin{array}{l}\text { Method- } \\
3\end{array}$ & 0.57 & 0.43 & 0.72 & 0.3342 \\
\hline & & $\begin{array}{l}\text { Method- } \\
4\end{array}$ & 0.53 & 0.38 & 0.67 & 0.7312 \\
\hline \multirow[t]{5}{*}{ Myelopathy-Related Symptoms } & \multicolumn{2}{|c|}{ Cobb Angle Method } & 0.62 & 0.48 & 0.76 & 0.0957 \\
\hline & \multirow[t]{4}{*}{$\begin{array}{l}\text { Area } \\
\text { Methods }\end{array}$} & $\begin{array}{l}\text { Method- } \\
1\end{array}$ & 0.58 & 0.45 & 0.72 & 0.2456 \\
\hline & & $\begin{array}{l}\text { Method- } \\
2\end{array}$ & 0.58 & 0.44 & 0.71 & 0.3007 \\
\hline & & $\begin{array}{l}\text { Method- } \\
3\end{array}$ & 0.60 & 0.46 & 0.74 & 0.1810 \\
\hline & & $\begin{array}{l}\text { Method- } \\
4\end{array}$ & 0.60 & 0.46 & 0.74 & 0.1651 \\
\hline \multirow{4}{*}{$\begin{array}{l}\text { Sympathetic or VA-Related } \\
\text { Symptoms }\end{array}$} & \multicolumn{2}{|c|}{ Cobb Angle Method } & 0.59 & 0.45 & 0.73 & 0.1989 \\
\hline & \multirow[t]{3}{*}{$\begin{array}{l}\text { Area } \\
\text { Methods }\end{array}$} & $\begin{array}{l}\text { Method- } \\
1\end{array}$ & 0.65 & 0.52 & 0.78 & 0.0380 \\
\hline & & $\begin{array}{l}\text { Method- } \\
2\end{array}$ & 0.64 & 0.51 & 0.78 & 0.0456 \\
\hline & & $\begin{array}{l}\text { Method- } \\
3\end{array}$ & 0.65 & 0.52 & 0.78 & 0.0380 \\
\hline \multicolumn{2}{|c|}{ Loading [MathJax]/jax/output/CommonHTML/jax.js } & Method- & 0.63 & 0.50 & 0.77 & 0.0627 \\
\hline
\end{tabular}


*Note. VA, vertebral artery; AUC, area under curve; $\mathrm{Cl}$, confidence interval

\section{Figures}

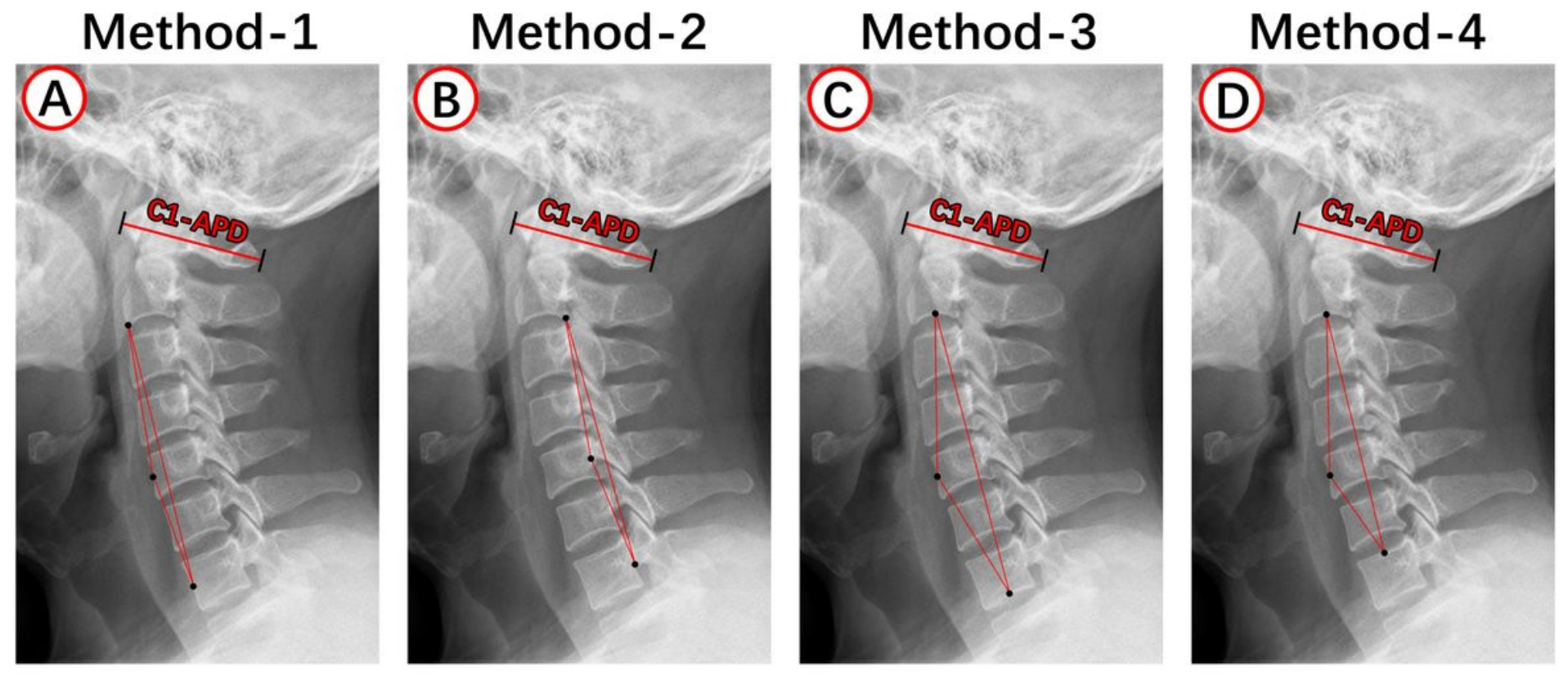

\section{Figure 1}

Methods of Constructing Cervical Sagittal Triangles A, Method-1 of constructing cervical sagittal triangle with "Anterior-inferior point of C7 - Midpoint of anterior edge of C5 - Midpoint of anterior edge of C7"; B, Method-2 of constructing cervical sagittal triangle with "Posterior-inferior point of $\mathrm{C} 7$ - Midpoint of posterior edge of C5 - Midpoint of posterior edge of C7"; C, Method-3 of constructing cervical sagittal triangle with "Midpoint of inferior endplate of C2 -- Midpoint of anterior edge of C5 - Midpoint of inferior endplate of C7"; D, Method-3 of constructing cervical sagittal triangle with "Midpoint of inferior endplate of C2 - Midpoint of anterior edge of C5 -- Midpoint of superior endplate of C7". 

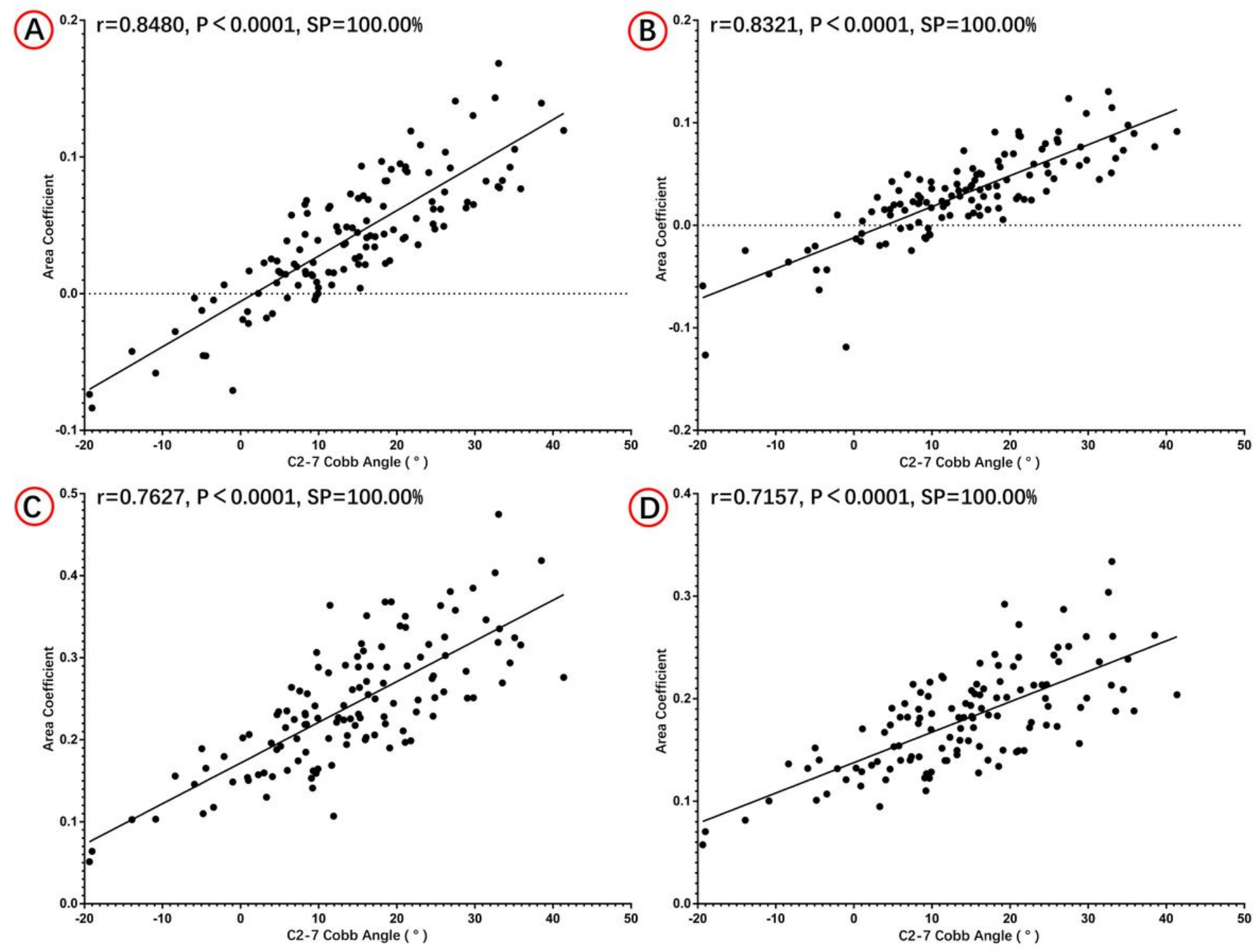

Figure 2

Pearson Correlation Analysis of Quantitative Results of Cervical Sagittal Morphology with Different Methods in Group A A, Pearson correlation analysis of quantitative results of cervical sagittal morphology with Cobb angle method and area Method- 1 in Group A, r=0.8480, P凶0.0001, statistical power $=100.00 \%$; , Pearson correlation analysis of quantitative results of cervical sagittal morphology with Cobb angle method and area Method-2 in Group A, $r=0.8321$, P凶0.0001, statistical power $=100.00 \%$; C, Pearson correlation analysis of quantitative results of cervical sagittal morphology with Cobb angle method and

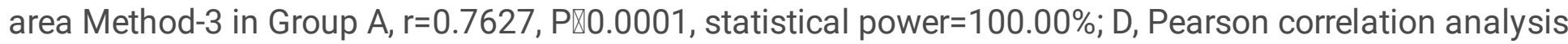
of quantitative results of cervical sagittal morphology with Cobb angle method and area Method-4 in Group A, $r=0.7157, P \otimes 0.0001$, statistical power $=100.00 \%$. 

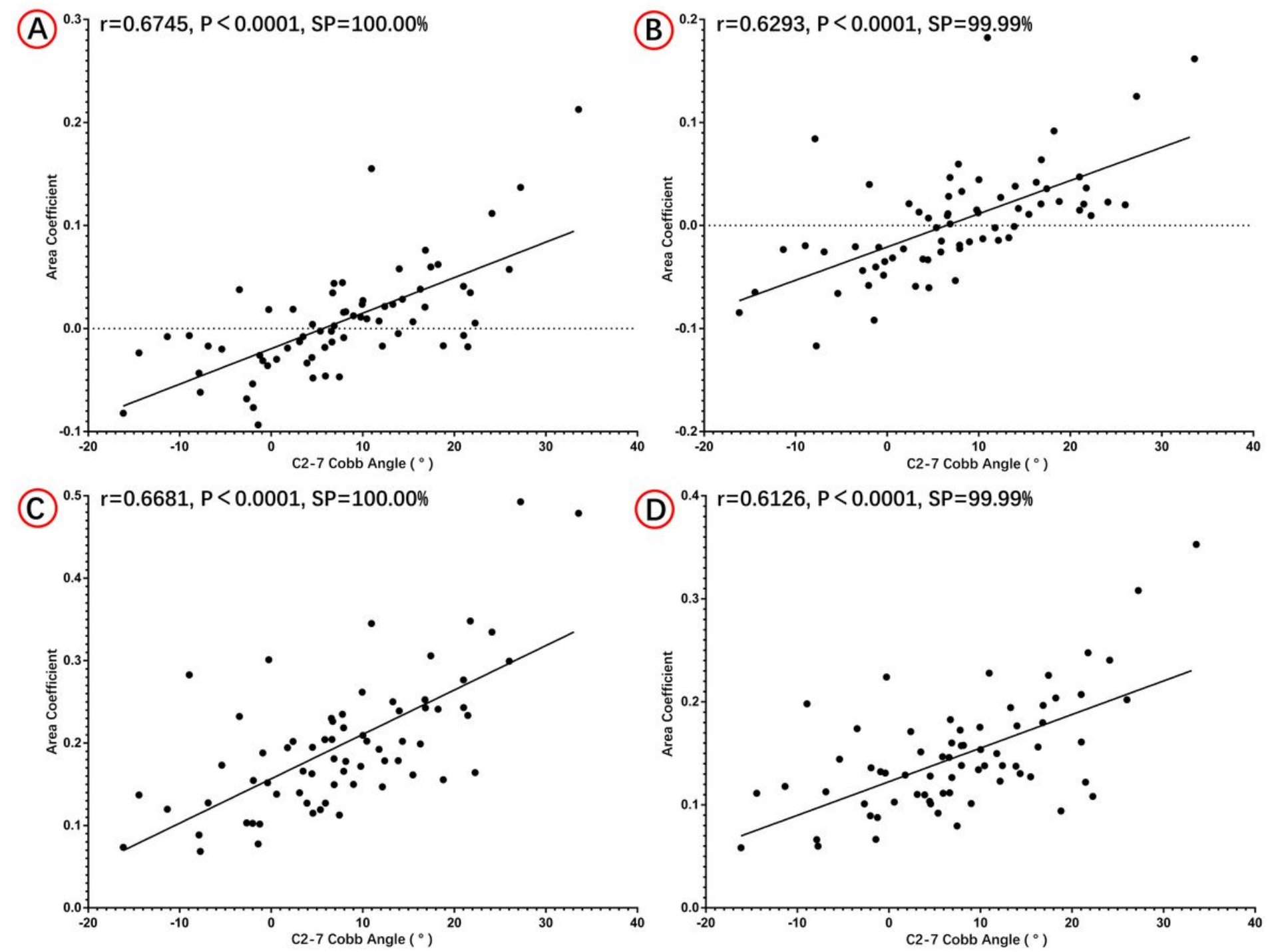

Figure 3

Pearson Correlation Analysis of Quantitative Results of Cervical Sagittal Morphology with Different Methods in Group B A, Pearson correlation analysis of quantitative results of cervical sagittal morphology with Cobb angle method and area Method- 1 in Group B, $r=0.6745$, $P \bowtie 0.0001$, statistical power $=100.00 \%$; Pearson correlation analysis of quantitative results of cervical sagittal morphology with Cobb angle method and area Method-2 in Group B, r=0.6293, P®0.0001, statistical power $=99.99 \%$; , Pearson correlation analysis of quantitative results of cervical sagittal morphology with Cobb angle method and area Method-3 in Group B, $r=0.6681, P \llbracket 0.0001$, statistical power $=100.00 \%$; D, Pearson correlation analysis of quantitative results of cervical sagittal morphology with Cobb angle method and area Method-4 in Group B, r=0.6126, Pख0.0001, statistical power $=99.99 \%$. 


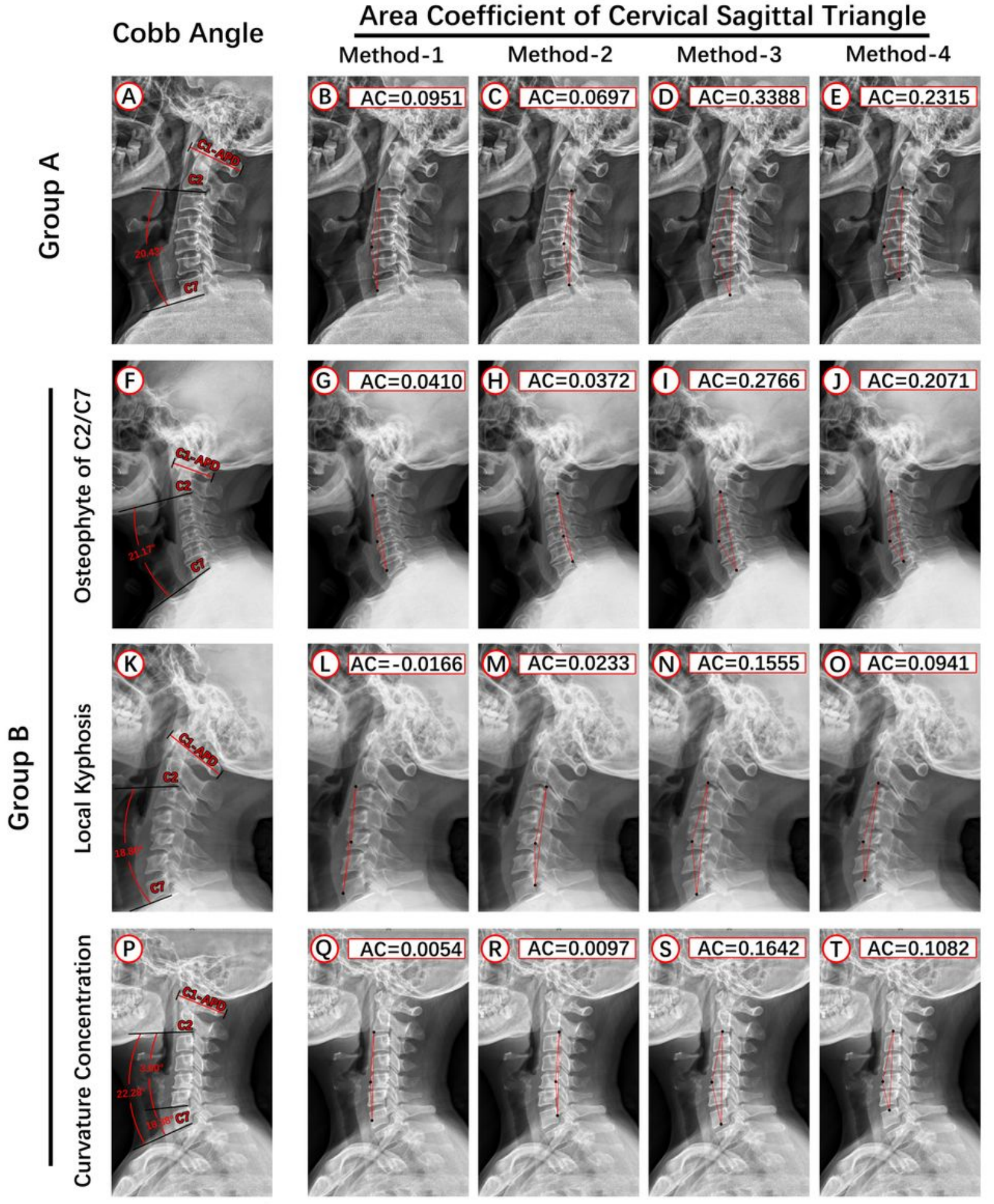

Figure 4

Typical Results of Cobb Angle Method and Area Methods in Group A and Group B A, Cobb angle of typical case in Group A $\left(20.43^{\circ}\right)$; B, AC with Method-1 of typical case in Group A (AC=0.0951); Figure-4C, AC with Method-2 of typical case in Group A ( $A C=0.0697) ; D, A C$ with Method-3 of typical case in Group A $(A C=0.3388) ; E, A C$ with Method-4 of typical case in Group $A(A C=0.2315) ; F$, Cobb angle of typical case in Loading [MathJax]/jax/output/CommonHTML/jax.js ate in C2/C7" (21.17 $)$; G, AC with Method-1 of typical case in 
Group B with "Paramorphia of inferior endplate in $C 2 / C 7$ " (AC=0.0410); $\mathrm{H}, \mathrm{AC}$ with Method-2 of typical case in Group B with "Paramorphia of inferior endplate in $C 2 / C 7$ " (AC=0.0372); I, AC with Method-3 of typical case in Group B with "Paramorphia of inferior endplate in $C 2 / C 7$ " (AC=0.2766); J, AC with Method4 of typical case in Group B with "Paramorphia of inferior endplate in $C 2 / C 7$ " (AC=0.2071); $K$, Cobb angle of typical case in Group B with "Local kypohsis" $\left(18.80^{\circ}\right)$; L, AC with Method-1 of typical case in Group B with "Local kypohsis" (AC=-0.0166); M, AC with Method-2 of typical case in Group B with "Local kypohsis" $(A C=0.0233) ; N, A C$ with Method-3 of typical case in Group B with "Local kypohsis" (AC=0.1555); O, AC with Method-4 of typical case in Group B with "Local kypohsis" ( $A C=0.0941)$; P, Cobb angle of typical case in Group B with "Curvature Concentration" (22.28 ); Q, AC with Method-1 of typical case in Group B with "Curvature Concentration" ( $A C=0.0054) ; R, A C$ with Method-2 of typical case in Group B with "Curvature Concentration" ( $A C=0.0097) ; S, A C$ with Method-3 of typical case in Group B with "Curvature Concentration" (AC=0.1642); T, AC with Method-4 of typical case in Group B with "Curvature Concentration" ( $\mathrm{AC}=0.1082)$.

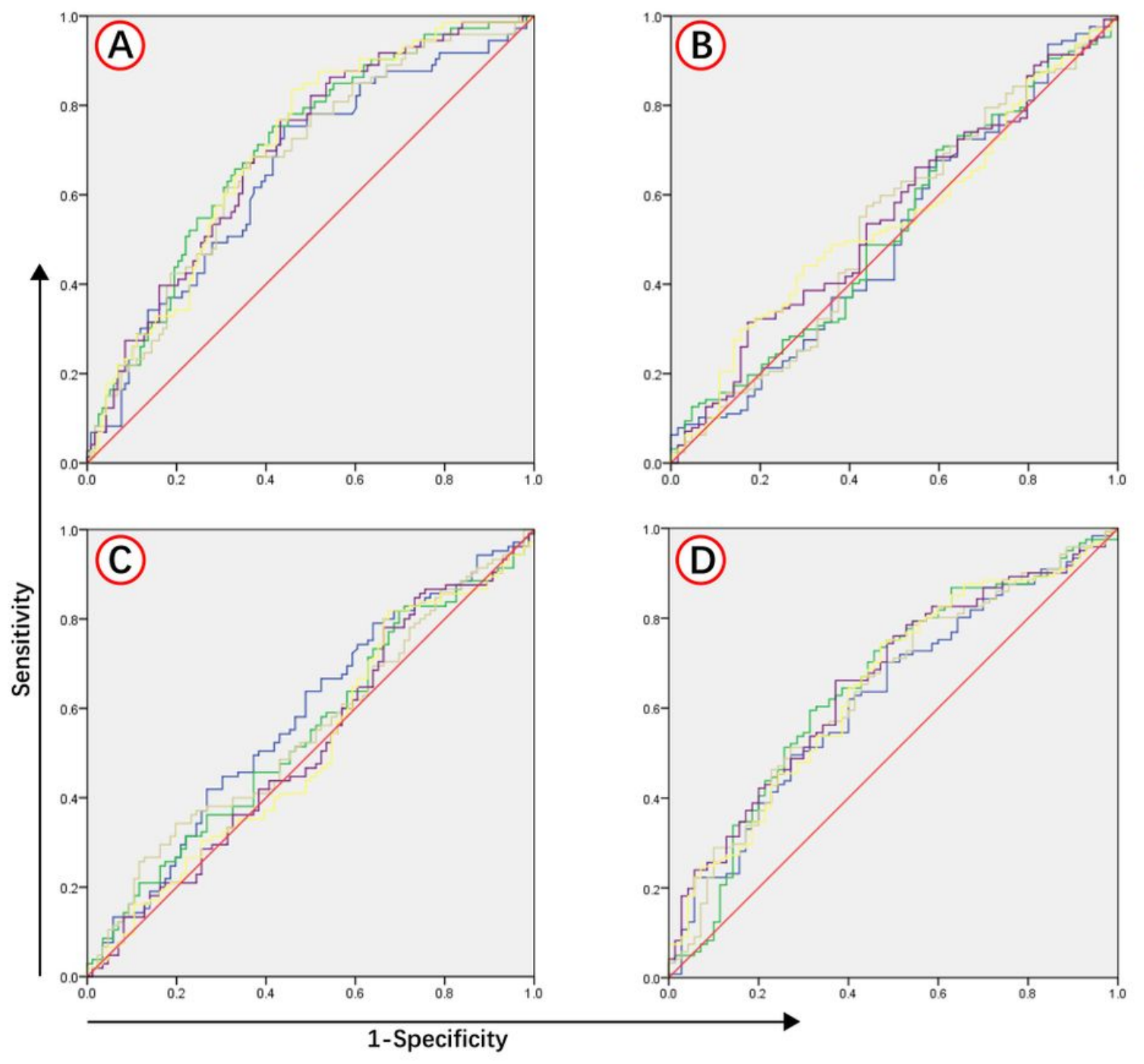

Figure 5

ROC Curve of Cervical Sagittal Morphology and Clinical Indicators in All Patients A, ROC curve for Loading [MathJax]/jax/output/CommonHTML/jax.js nonoccurrence of "Neck or Shoulder Pain" in all included 
patients; B, ROC curve for diagnostic value of different methods in the nonoccurrence of "Arm Pain" in all included patients; $\mathrm{C}, \mathrm{ROC}$ curve for diagnostic value of different methods in the nonoccurrence of "Myelopathy-Related Symptoms" in all included patients; D, ROC curve for diagnostic value of different methods in the nonoccurrence of "Sympathetic or VA-Related Symptoms" in all included patients.
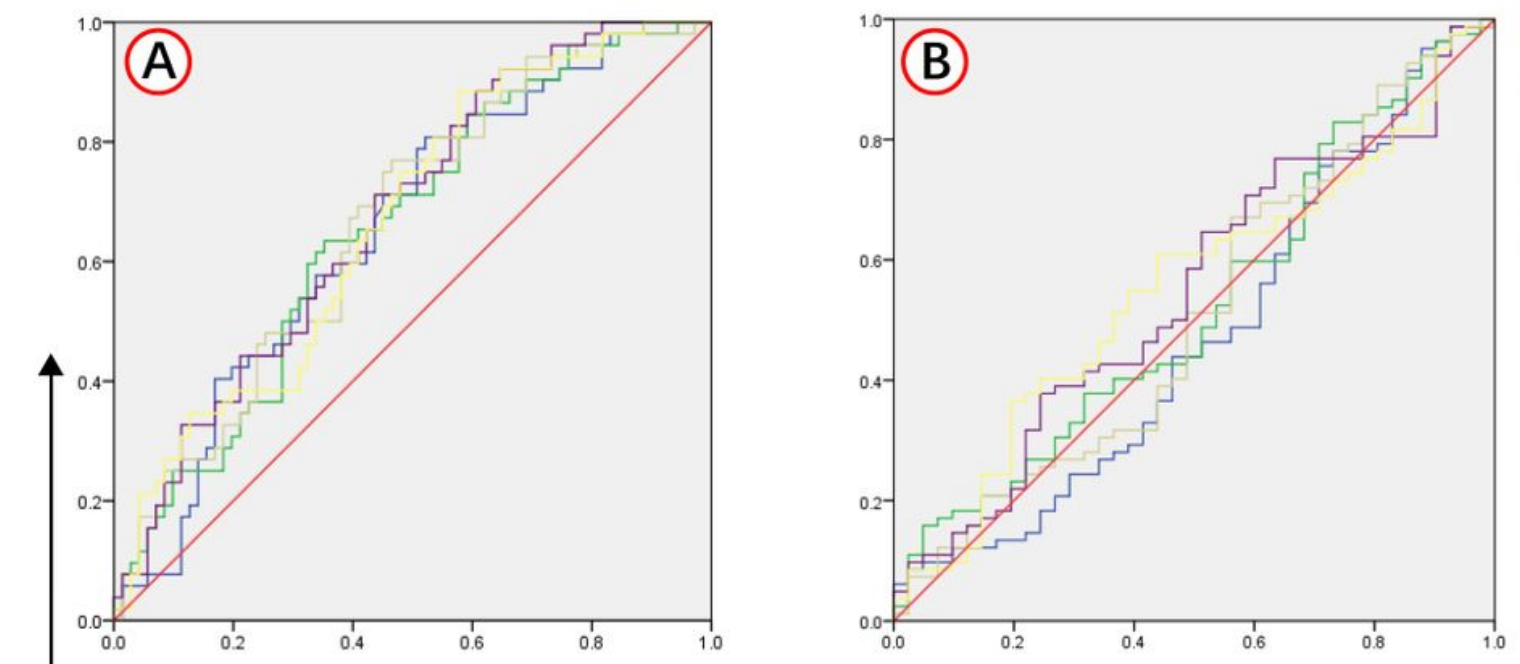

- Cobb Angle Method

- Area Method-1

- Area Method-2

- Area Method-3

Area Method-4

- Reference Line

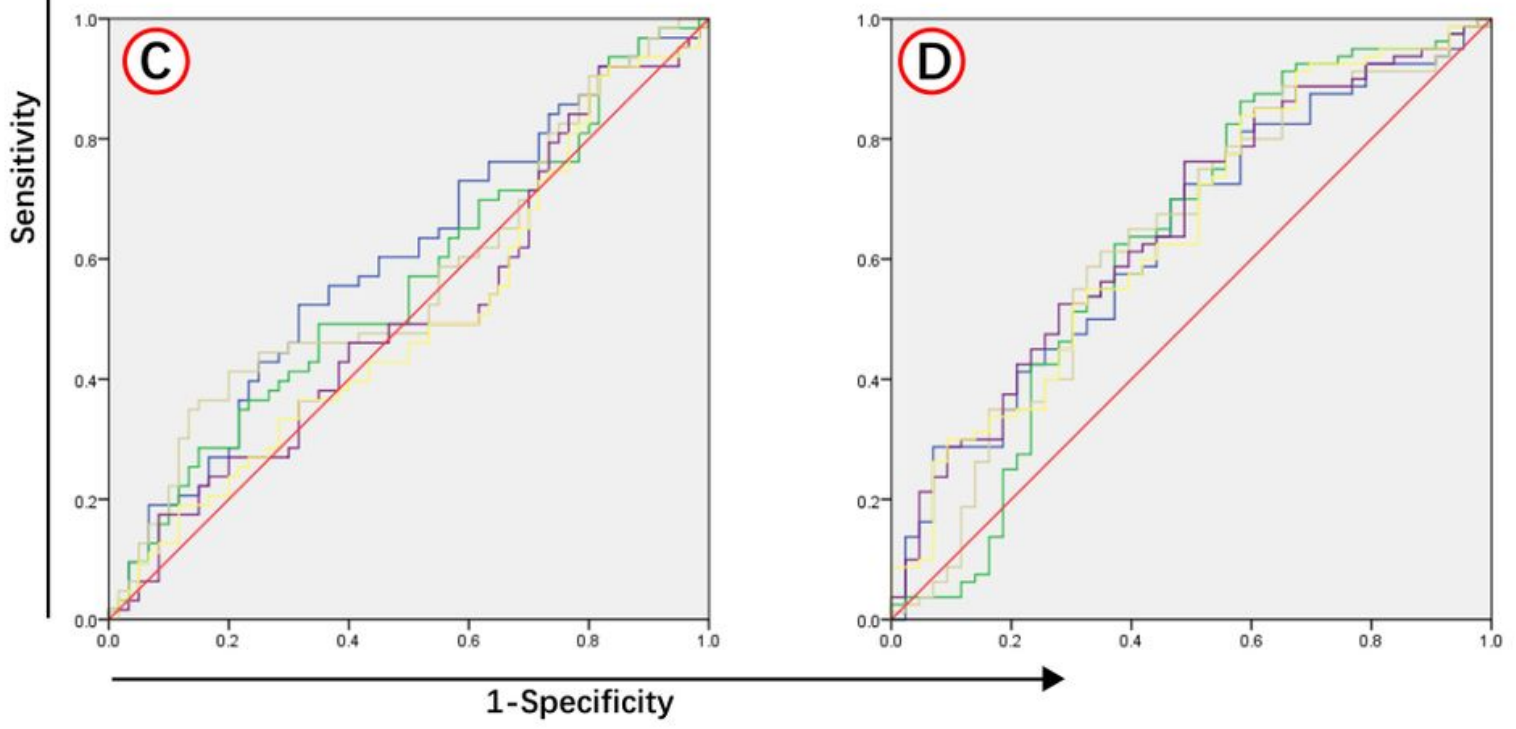

\section{Figure 6}

ROC Curve of Cervical Sagittal Morphology and Clinical Indicators in Group A A, ROC curve for diagnostic value of different methods in the nonoccurrence of "Neck or Shoulder Pain" in Group A; B, ROC curve for diagnostic value of different methods in the nonoccurrence of "Arm Pain" in Group A; C, ROC curve for diagnostic value of different methods in the nonoccurrence of "Myelopathy-Related Symptoms" in Group $A ; D, R O C$ curve for diagnostic value of different methods in the nonoccurrence of "Sympathetic or VARelated Symptoms" in Group A. 

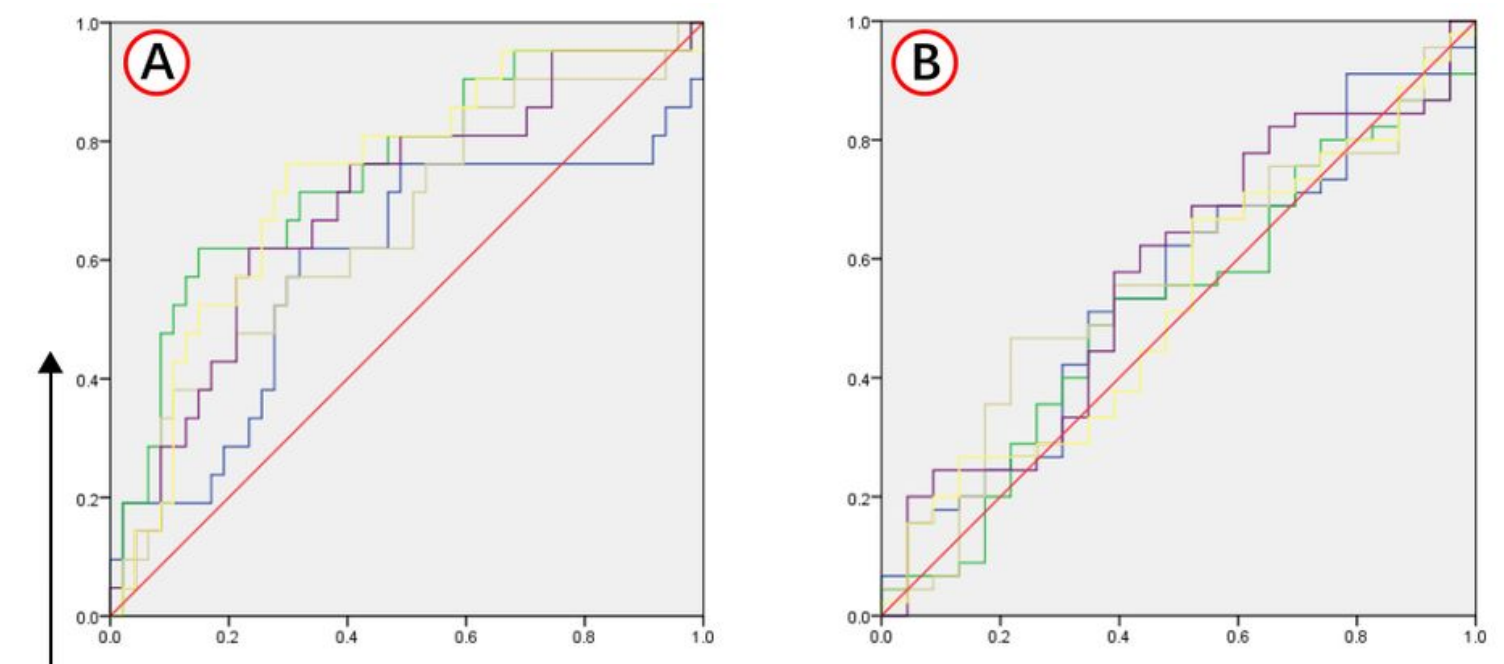

Cobb Angle Method

- Area Method-1

- Area Method-2

- Area Method-3

Area Method-4

- Reference Line

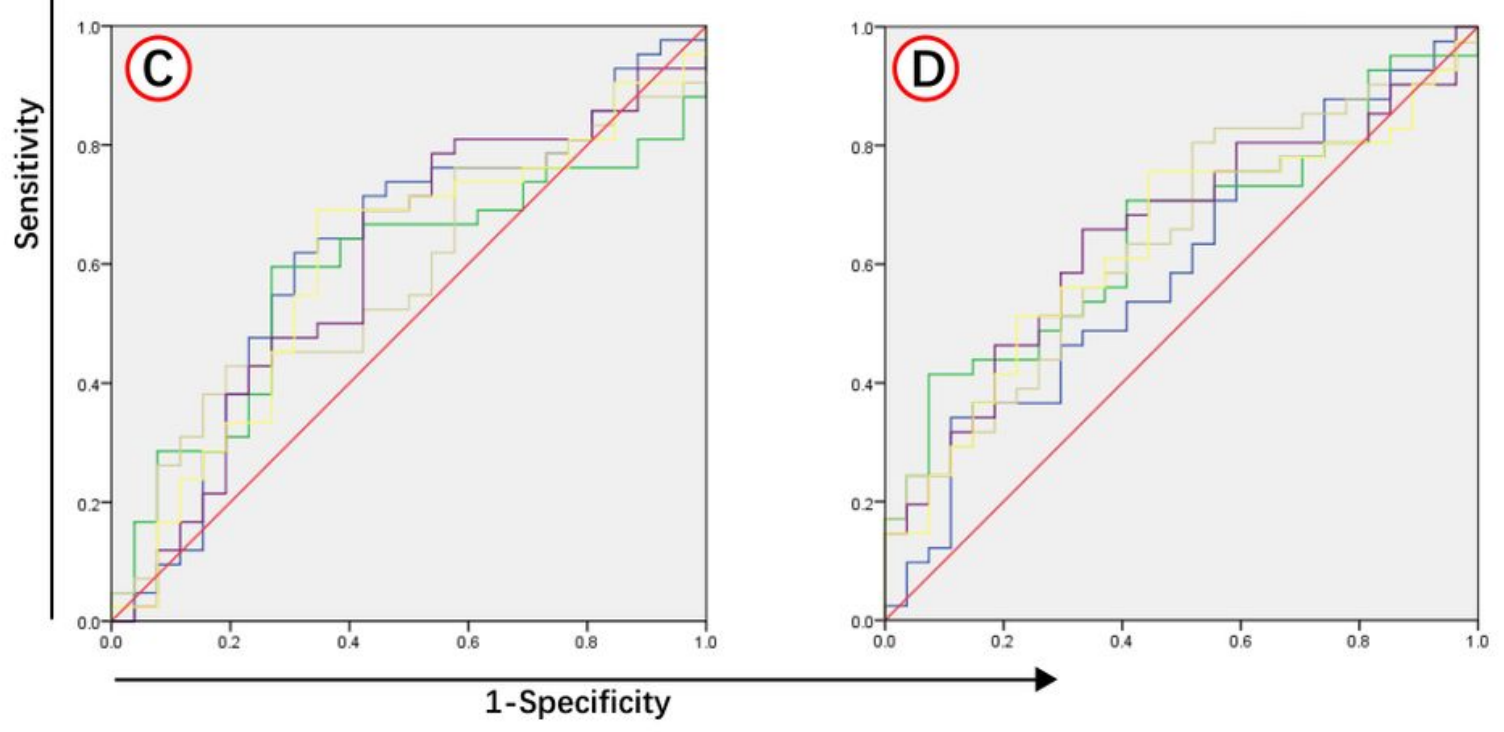

\section{Figure 7}

ROC Curve of Cervical Sagittal Morphology and Clinical Indicators in Group B A, ROC curve for diagnostic value of different methods in the nonoccurrence of "Neck or Shoulder Pain" in Group B; B, ROC curve for diagnostic value of different methods in the nonoccurrence of "Arm Pain" in Group B; C, ROC curve for diagnostic value of different methods in the nonoccurrence of "Myelopathy-Related Symptoms" in Group B; D, ROC curve for diagnostic value of different methods in the nonoccurrence of "Sympathetic or VARelated Symptoms" in Group B. 


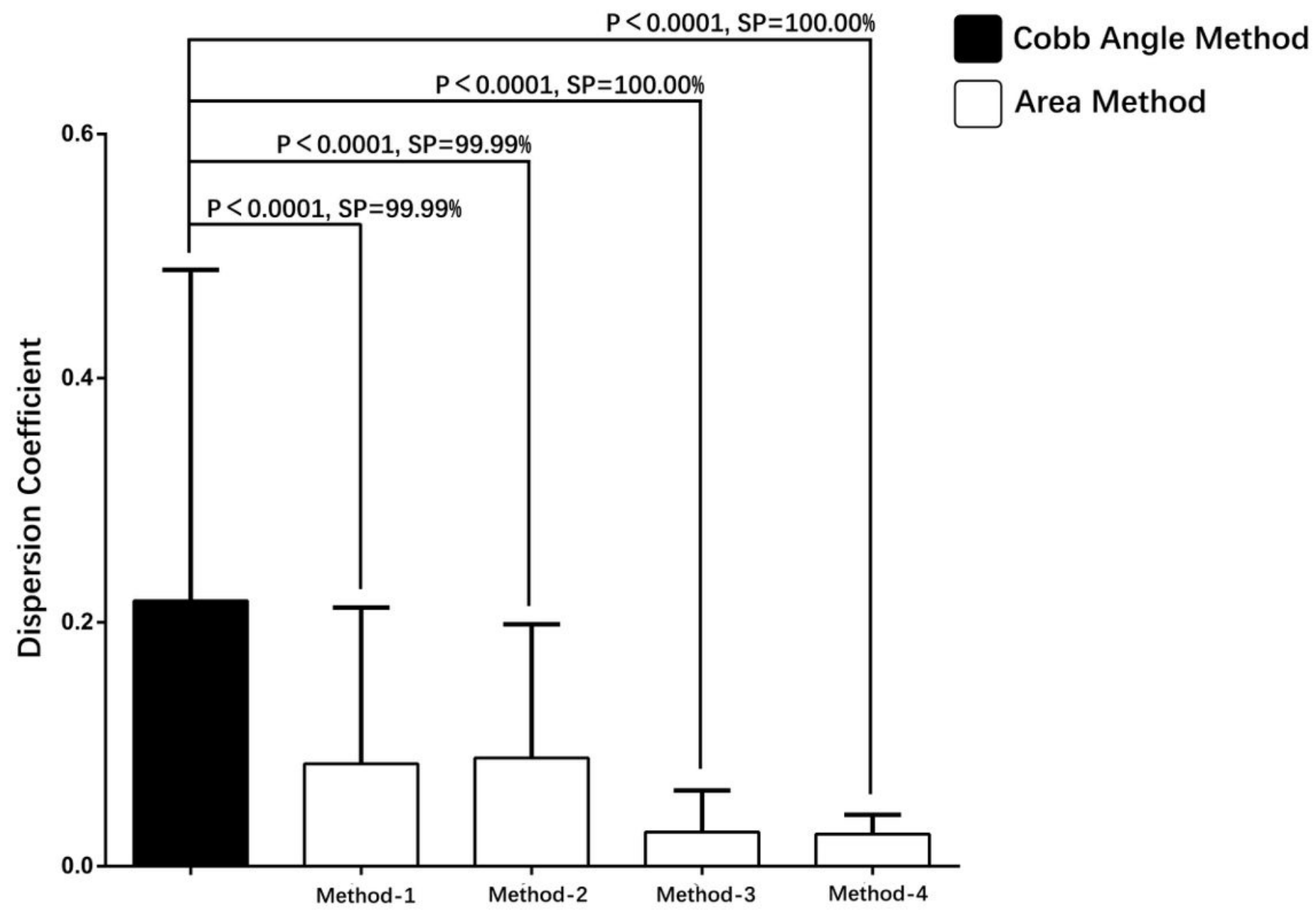

Figure 8

Comparison of Dispersion Coefficients for Results in Quantifying Cervical Sagittal Morphology with Different Methods Compared with the Cobb angle method, the dispersion coefficients of Method-1 (P区 0.0001 , statistical power $=99.99 \%)$, Method-2 (P凶0.0001, statistical power=99.99\%), Method-3 (P凶0.0001, statistical power $=100.00 \%)$, and Method-4 (Pख0.0001, statistical power=100.00\%) were all significantly lower. 

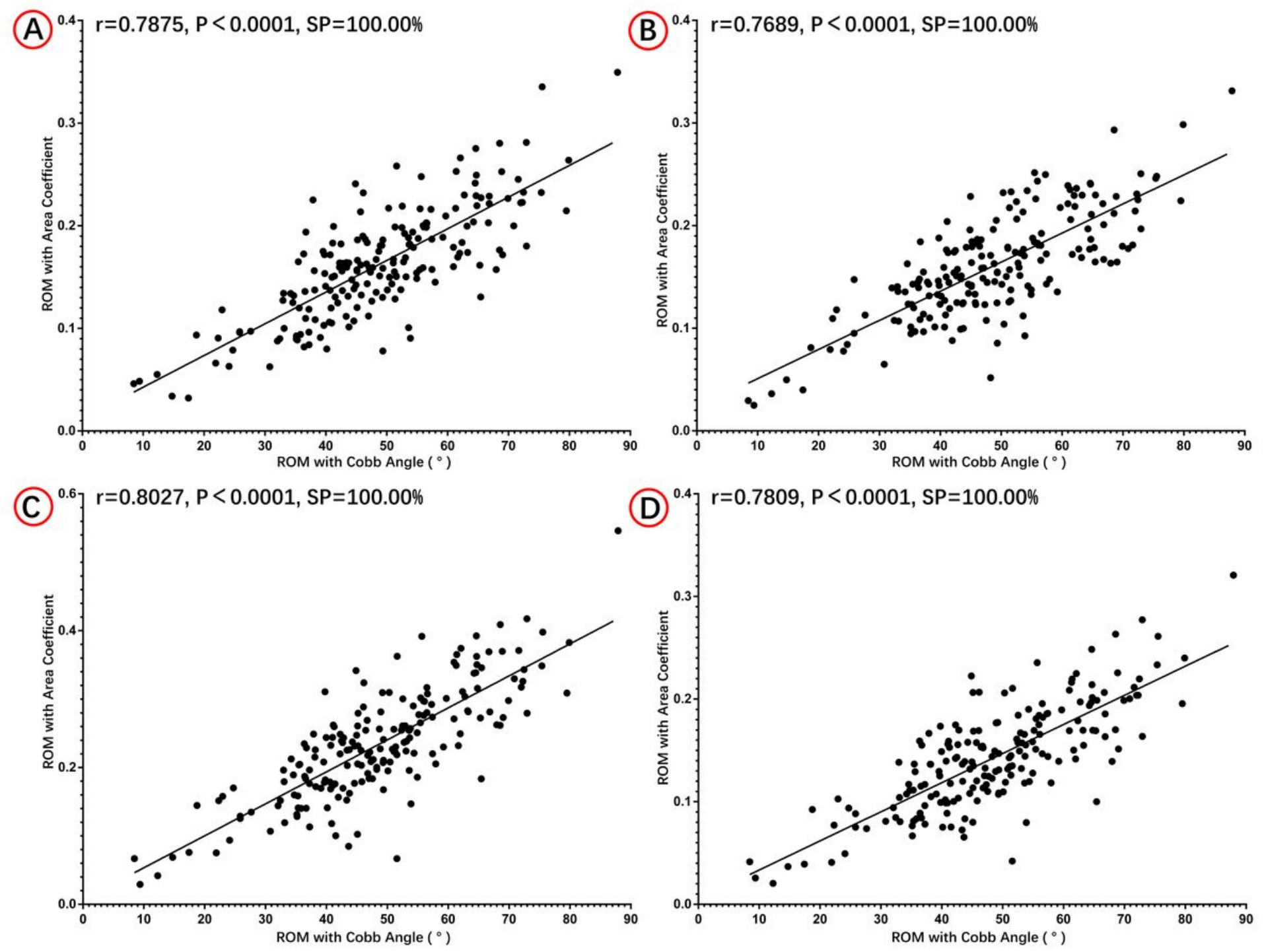

Figure 9

Pearson Correlation Analysis of Quantitative Results of Cervical ROM with Different Methods A, Pearson correlation analysis of quantitative results of cervical ROM with Cobb angle method and area Method-1, $r=0.7875, P \otimes 0.0001$, statistical power $=100.00 \%$; , Pearson correlation analysis of quantitative results of cervical ROM with Cobb angle method and area Method-2, r=0.7689, $\mathrm{P} \otimes 0.0001$, statistical power $=100.00 \%$; C, Pearson correlation analysis of quantitative results of cervical ROM with Cobb angle method and area Method-3, $r=0.8072, P \llbracket 0.0001$, statistical power $=100.00 \%$; , Pearson correlation analysis of quantitative results of cervical ROM with Cobb angle method and area Method-4, $r=0.7809, P \square$ 0.0001 , statistical power $=100.00 \%$.

\section{Supplementary Files}

This is a list of supplementary files associated with this preprint. Click to download. 